\title{
Evaluation and Diagnosis of Tibial Bone Stress Injuries in Adolescents: Imaging and Nomenclature
}

Eric D. Nussbaum, Med, LAT, ATC'; Bryan Holtzman, BA ${ }^{2,3}$; Katherine H. Rizzone, MD, MPH4; Adam S. Tenforde, MD ${ }^{2,5,6}$; Mark E. Halstead, $M D^{7}$; Corinna C. Franklin $M D^{8}$; Kathryn E. Ackerman, $M D, M P H^{2,6,9}$

${ }^{1}$ Department of Orthopaedic Surgery, Rutgers, Robert Wood Johnson Medical School, New Brunswick, NJ; ${ }^{2}$ Division of Sports Medicine, Boston Children's Hospital, Boston, MA; ${ }^{3}$ Perelman School of Medicine at the University of Pennsylvania, Philadelphia, PA; ${ }^{4}$ Department of Orthopaedics, University of Rochester Medical Center, Rochester, NY; ${ }^{5}$ Spaulding Rehabilitation Hospital, Charlestown, MA; ${ }^{6}$ Harvard Medical School, Boston, MA; ${ }^{7}$ Washington University School of Medicine and St. Louis Children's Hospital, St. Louis, MO; ${ }^{8}$ Shriners Hospital for Children-Philadelphia, Philadelphia, PA; ${ }^{9}$ Neuroendocrine Unit, Massachusetts General Hospital, Boston, MA

Correspondence to: Kathryn E. Ackerman, MD, MPH, Boston Children's Hospital, Division of Sports Medicine, 319 Longwood Avenue-6 ${ }^{\text {th }}$ Floor, Boston, MA 02115, U.S, E-mail: kathryn.ackerman@childrens.harvard.edu

Received: October 29, 2021; Accepted: January 21, 2022; Published: February 1, 2022

DOI: 10.55275/JPOSNA-2022-0015

\begin{abstract}
:
Tibial bone stress injuries (BSIs) are common injuries experienced by active adolescent athletes. The current literature lacks consensus of BSI nomenclature and appropriate use of imaging modalities. The purpose of this Current Concept Review is to identify existing classification of atraumatic tibial pain/BSI, propose unifying nomenclature, and review imaging tools available to clinicians caring for young athletes. Unified terminology and recommended imaging modalities for the adolescent athlete with these injuries would improve patient care and professional communication. We propose using "Bone Stress Injury" (BSI) to describe overuse injury of the tibia with associated physical examination findings. Radiography is recommended as the first imaging modality, and MRI should be considered to confirm diagnosis and determine grade of injury.
\end{abstract}

\section{Key Concepts:}

- Atraumatic tibial pain is a common injury experienced by pediatric and adolescent athletes, but no uniform diagnostic terminology currently exists for appropriate identification and management.

- "Bone stress injury" should be used as a unifying term for "stress fracture," "stress reaction," and other phrases that are inconsistently used to define overuse injuries of the bone.

- MRI is the gold-standard by which bone stress injuries of the tibia can be graded for severity.

- Physicians are encouraged to maintain a broad differential diagnosis when treating tibial pain to avoid missing a catastrophic diagnosis (e.g., sarcoma) in a young athlete. 


\section{Introduction}

Bone stress injuries (BSIs) are estimated to affect up to $20 \%$ of adolescent athletes, with variability based on primary sport. ${ }^{1}$ The tibia is the most common location for injury, accounting for $19-54 \%$ of total injuries by anatomical distribution, ${ }^{1-4}$ and the incidence of these injuries is rising: in 2005, the incidence in children 6-18 was 1.37 per 100,000 outpatients visits, and in 2015 , the incidence was 5.32 per $100,000 .{ }^{5}$ BSI may occur most frequently in athletes between the ages of 15 and 24, corresponding with stage in development for reaching peak bone mass. ${ }^{3,6,7}$ The proposed mechanism for injury is repetitive load exceeding bone strength, resulting in micro damage that accumulates and may progress to complete fracture. ${ }^{8}$ BSIs occur when bone resorption exceeds ossification during normal remodeling. ${ }^{9}$

Specifically, the posterior medial cortex (compression side) of the tibial diaphysis is the most common anatomic region of injury. Anteromedial tibial diaphysis injury (tension side) is less common, though such an injury is considered high risk to progress to complete fracture. ${ }^{10}$ The injury may isolate to one tibia or occur bilaterally. ${ }^{11}$ Athletes participating in land-based sports involving running, jumping, and repetitive stress are at higher risk for BSI, and the incidence is higher in female athletes. ${ }^{7,12}$

Current literature lacks consensus of BSI classification and appropriate use of imaging. Consequently, the actual incidence of tibial BSI may be higher than currently noted. Clinical presentation and outcomes based on imaging of BSI may vary among adolescents. Injury classification, severity, or grade may differ substantially according to imaging modalities used and location of the injury. Appropriate diagnosis and management of tibial BSIs is made more difficult by the lack of common nomenclature and imaging consensus. With the frequency of various grades of BSI in adolescent athletes, the effects of such injuries on return to play, and the potential consequences radiation dosing can have on the growing skeleton, it is important to discuss unifying nomenclature for BSI and to review imaging modalities available to clinicians caring for young athletes.

\section{Bone Stress Injury of the Tibia}

Lower leg pain is common in athletes and has variable reported incidence, partially reflecting inconsistent terminology to describe injury. ${ }^{13}$ During our review, we identified 32 different diagnoses used to describe atraumatic, exercise-related shin pain. The terms stress fracture, fatigue fracture, stress reaction, shin splints, periostitis, bone marrow edema, and medial tibial stress syndrome (MTSS) are the most frequently - and often interchangeably - used terms in the literature. ${ }^{13-21}$ Inconsistency of terminology creates ambiguity among clinicians, patients, coaches, and parents who are trying to manage the problem. In the absence of advanced imaging, however, many clinicians rely on clinical examination and general characterizations of shin pain and may use outdated terminology.

The term "shin splints" is frequently used to describe non-descript shin pain related to physical activity. Shin splints are reportedly associated with a theoretical pulling away of muscular attachments, causing an inflammation of the periosteum. They have long been considered the cause of MTSS. ${ }^{22}$ However, while recent studies have suggested that shin splints cannot be imaged by MRI, ${ }^{23}$ there is ample evidence to warrant exclusion of the traction-based injury caused by the tibialis posterior or flexor halluces longus attachment to the tibia as a possible mechanism of MTSS. ${ }^{22}$ MTSS may not represent inflammation of the periosteum but a progression to symptomatic BSI. ${ }^{24}$ Because of the routine occurrence and use of benign terminology like shin splints or MTSS, many athletes will overlook the significance of the bone injury and continue with their training; these injuries exist on the spectrum of BSI severity. Consequently, it is likely that tibial BSI are under-reported, as athletes may continue to train with ongoing pain and worsening injury. ${ }^{25}$

Because BSI can occur as a spectrum of injury from periosteal irritation to complete fracture, often on a continuum known as a "stress reaction" prior to a visible fracture line, not all injuries to bone should be referred 
to as "stress fractures." Misclassification is common: most diagnosed "stress fractures" do not demonstrate the presence of fracture line on imaging. ${ }^{21} \mathrm{~A}$ fracture line is apparent in only $1-4 \%$ of injuries localized to the tibia that present with exercise-induced shin pain. ${ }^{26}$ Using "stress fracture" terminology to denote any injury isolated to the bone may overestimate the incidence of true stress fractures.

Unified classification in terminology of BSI may contribute to earlier, more efficient diagnosis, less time lost to injury, decreased patient confusion, and improved patient care. Timely diagnosis can improve return to sport and reduce disruptions to an athletic career. ${ }^{27}$ Based on advances in our understanding of overuse injuries to bone, BSI is the preferred terminology to use in the diagnosis and management of this injury in adolescent athletes and may help improve our understanding for treatment and prevention. ${ }^{28}$

\section{Imaging in the Diagnosis of Tibial BSI}

Imaging is commonly used in the evaluation and treatment of tibial BSI. ${ }^{29,30}$ For example, identifying BSI at earlier stages may help facilitate an earlier return to play. ${ }^{7}$ The benefits - manifest as improved patient outcomes - of any study should outweigh the costs and risks levied on the patient. Given that pediatric tissue is significantly more sensitive to ionizing radiation (in part due to increased mitotic rate and longer remaining lifespans compared to adults), special considerations should be granted to limiting ionizing radiation when evaluating pediatric and adolescent athletes. ${ }^{31}$

\section{Plain Radiographs}

Radiographs (x-rays) are the most common form of diagnostic imaging for the lower leg. ${ }^{32,33}$ Despite poor sensitivity early in the disease process, the American College of Radiology recommends x-ray as the best initial imaging modality in the workup for tibial BSI due to low cost and widespread availability. ${ }^{32,34,35} \mathrm{In}$ the pediatric patient, AP and lateral view radiographs of the tibia/fibula will emit approximately $0.002 \mathrm{mSv}$ of radiation combined, a dose equivalent to 6 hours of normal sun exposure. ${ }^{32}$ Most exercise-related tibial BSIs do not show evidence of a break in the bone cortex on initial radiographs. ${ }^{27,36}$ Typically, radiographs will show evidence of BSI once the healing response of bone has begun, ${ }^{36}$ and the average/mean time interval between onset of symptoms and radiographic diagnosis ranges from 2 to 6 weeks. ${ }^{37}$ Furthermore, up to $50 \%$ of BSIs may remain radiographically occult. ${ }^{38}$ When BSI is detectable on radiograph, it is usually associated with increased clinical significance and higher BSI grade. ${ }^{18,39,40}$ In general, radiography has low initial sensitivity for detecting tibial BSI, ranging from 3 to $29 \%$, and less than $50 \%$ of serial radiographs will demonstrate changes consistent with this diagnosis. ${ }^{34,41}$ Therefore, interpretation of radiographs should be in part based on clinical suspicion for BSI, as adolescent athletes tend to continue training and propagate their injury if they are reassured by a false negative radiograph. The pathognomonic radiographic diagnosis of anterior tibial cortex stress injury is the presence of a "dreaded black line" on lateral view, ${ }^{42}$ which is considered high risk for development of frank fracture, though only a minority of tibial BSIs will be in this category.

The first sign of BSI on radiograph may be reactive periosteal inflammation and inflammation of the overlying subcutaneous tissues. Both are difficult to appreciate without comparative views. These radiographic signs are not diagnostic of BSI; rather, they are suggestive of injury and indications for further imaging. ${ }^{43}$ Initial signs of bony injury on radiography may include the appearance of "layers of eggs shell,"44 periosteal or endosteal new bone, ${ }^{37,39,45}$ sclerosis, ${ }^{46}$ or a "gray cortex sign" or "dreaded black line," both of which represent a cortical fracture on radiograph. ${ }^{46-48}$ However, Schilcher and colleagues performed biopsies on tibiae that demonstrated "dreaded black line" and found that the radiographic fracture line is not a fracture on the microscopic level but instead represents resorption cavities lined with active osteoblasts and immature bone. ${ }^{42}$ This site is a weakened area of bone that is histologically different from a frank fracture. ${ }^{42}$ Other findings that can be visualized on radiography 
include endosteal thickening, roughening, or "fluffiness" along the intramedullary canal. ${ }^{49}$ Radiographic osseous changes that correspond with exam findings of pain are significantly more likely to have features on MRI that would confirm diagnosis of BSI. ${ }^{39}$ Therefore, the clinical presentation of the patient remains a mainstay of assessment despite the radiographic findings. ${ }^{21}$

Bone lesions and infection are less common sources of leg pain in pediatric patients that can be visualized using plain radiographs. Primary bone tumors are the sixth most common neoplasm in pediatric patients, ${ }^{50}$ although most in this age population are benign. ${ }^{51}$ Consequently, clinicians should not overlook the importance of imaging in the pediatric population who present with shin pain.

\section{Magnetic Resonance Imaging}

When initial radiographs are negative and clinical suspicion for BSI is high, MRI without contrast is recommended by the American College of Radiology. ${ }^{32}$ MRI may be the best imaging modality for visualizing BSI for the pediatric population because it uses nonionizing radiation, provides excellent imaging resolution, and is both highly sensitive and specific. ${ }^{19,36,52}$ A 2016 systematic review found MRI to be the most sensitive and specific imaging modality for BSI; the authors also recommended MRI for patients with negative radiographs and a high clinical suspicion for a high-risk BSI. ${ }^{27}$ MRI demonstrates stress abnormalities as early as bone scintigraphy ${ }^{53}$ and is more sensitive and specific than radiography, bone scintigraphy, and computed tomography when used for BSI imaging. Furthermore, the severity of change in MRI corresponds with the clinical severity. ${ }^{15}$

When using MRI, fluid-sensitive sequences are typically recommended for detection of BSI. ${ }^{54}$ A key feature of BSI is bone marrow edema, which is demonstrated by high signal on fat-saturated T2-weighted and short tau inversion recovery (STIR) images. ${ }^{36}$ Fat-saturated T2 sequences and STIR improve sensitivity by suppressing fat signal, which can obscure edema on non-fat-saturated T2-weighted sequences. ${ }^{55}$ A hypointense fracture line may be seen on T1 and T2 images. ${ }^{56}$ Early tibial BSI may be detected on fat-saturated T2 and STIR images with bone marrow or periosteal edema as well as cortical abnormalities. ${ }^{57}$ Kijowski and colleagues defined several MRI features of tibial BSI: periosteal edema, linear high T2 signal immediately adjacent to the outer cortex; bone marrow edema, low T1 and high T2 within the canal; cortical abnormality (Table 1). ${ }^{39}$

MRI may be useful in evaluating other causes of leg pain in athletes, such as chronic exertional compartment syndrome and peripheral neuropathy. ${ }^{55}$ Also, soft tissue injuries can be clearly differentiated using MRI. MRI has similar sensitivity to, but greater specificity than, bone scintigraphy to detect BSI. ${ }^{60}$

Extrapolation of MRI findings in adults may not be completely applicable to the adolescent population, but these grading scales serve as the best reference in the absence of formal adolescent-focused guidelines. The adaptation of grading systems to help determine return to play are helpful, but none of the studies are large or diverse enough to make convincing arguments for change in nomenclature from Fredericson, et al. ${ }^{18}$ Ultimately, the scale proposed by Fredericson and colleagues was useful to bring some clarity to the 32 different terms used to describe BSI. ${ }^{18}$ See Figures 1 through 4 for examples of Fredericson, et al. grading of tibial BSI.

Changes on MRI consistent with BSI may not correspond to clinical symptoms. ${ }^{45,61}$ The findings of bone edema on MRI may represent osseous remodeling or localized changes in bone mineral density. ${ }^{62,63} \mathrm{~A}$ study of 55 asymptomatic Special Forces recruits found that endosteal edema $>100 \mathrm{~mm}$ in length had a high likelihood of progressing over time. ${ }^{64}$ Those with edema measuring $<100 \mathrm{~mm}$ did not progress and often resolved over time. ${ }^{64}$

Leg pain can be observed on clinical exam in adolescent athletes without corresponding changes on radiographs and MRI. ${ }^{18,26,65}$ Clinicians must remember that MRI is not $100 \%$ sensitive. ${ }^{66}$ The less-common longitudinal tibial stress fracture may also be seen on MRI but is frequently missed. Finding a cleft in the bone on one or more images is essential for diagnosis and axial images 
Table 1. Grading Scale for Categorizing BSI on MRI

\begin{tabular}{|c|c|c|c|c|c|c|c|}
\hline $\begin{array}{l}\text { MRI } \\
\text { Grade }\end{array}$ & $\begin{array}{l}\text { Fredericson, } \\
\text { et al. }{ }^{18} *\end{array}$ & $\begin{array}{l}\text { Arendt and } \\
\text { Griffiths }^{14}\end{array}$ & $\begin{array}{l}\text { Kiuru, } \\
\text { et al. }{ }^{58}\end{array}$ & $\begin{array}{l}\text { Kijowski, } \\
\text { et al. }{ }^{39}\end{array}$ & $\begin{array}{l}\text { Nattiv, } \\
\text { et al. }{ }^{59}\end{array}$ & $\begin{array}{l}\text { Kaeding and } \\
\text { Miller }^{10}\end{array}$ & $\begin{array}{l}\text { Gmachowska, } \\
\text { et al.11 }\end{array}$ \\
\hline Grade 1 & $\begin{array}{l}\text { Mild to moderate } \\
\text { periosteal edema } \\
\text { on T2 } \\
\text { Normal marrow } \\
\text { on T1 \& T2 }\end{array}$ & $\begin{array}{l}\text { Positive } \\
\text { signal } \\
\text { change on } \\
\text { STIR }\end{array}$ & $\begin{array}{l}\text { Endosteal } \\
\text { edema }\end{array}$ & $\begin{array}{l}\text { Periosteal } \\
\text { edema }\end{array}$ & $\begin{array}{l}\text { Mild marrow } \\
\text { or periosteal } \\
\text { edema on } \mathrm{T} 2\end{array}$ & $\begin{array}{l}\text { Imaging } \\
\text { evidence of } \\
\text { stress fracture, } \\
\text { no fracture line, } \\
\text { no pain }\end{array}$ & $\begin{array}{l}\text { Periosteal } \\
\text { edema }\end{array}$ \\
\hline Grade 2 & $\begin{array}{l}\text { Moderate to } \\
\text { severe periosteal } \\
\text { edema on } \mathrm{T} 2 \\
\text { Marrow edema on } \\
\mathrm{T} 2 \text { but not } \mathrm{T} 1\end{array}$ & $\begin{array}{l}\text { Positive } \\
\text { signal } \\
\text { change on } \\
\text { STIR and } \\
\text { positive T2 }\end{array}$ & $\begin{array}{l}\text { Periosteal } \\
\text { and endosteal } \\
\text { edema }\end{array}$ & $\begin{array}{l}\text { Periosteal } \\
\text { and marrow } \\
\text { edema }\end{array}$ & $\begin{array}{l}\text { Moderate } \\
\text { marrow or } \\
\text { periosteal } \\
\text { edema and } \\
\text { positive T2 }\end{array}$ & $\begin{array}{l}\text { Imaging } \\
\text { evidence of } \\
\text { stress fracture, } \\
\text { no fracture line, } \\
\text { pain }\end{array}$ & $\begin{array}{l}\text { Periosteal and } \\
\text { marrow edema }\end{array}$ \\
\hline Grade 3 & $\begin{array}{l}\text { Moderate to } \\
\text { severe periosteal } \\
\text { edema on T2 } \\
\text { Marrow edema on } \\
\text { T1 and T2 }\end{array}$ & $\begin{array}{l}\text { Positive } \\
\text { STIR, T1, } \\
\text { and T2 }\end{array}$ & $\begin{array}{l}\text { Muscle, } \\
\text { periosteal, } \\
\text { and endosteal } \\
\text { edema }\end{array}$ & $\begin{array}{l}\text { Liner } \\
\text { intracortical } \\
\text { fracture line }\end{array}$ & $\begin{array}{l}\text { Severe } \\
\text { marrow or } \\
\text { periosteal } \\
\text { edema on } \mathrm{T} 1 \\
\text { or T2 }\end{array}$ & $\begin{array}{l}\text { Non-displaced } \\
\text { fracture line }\end{array}$ & $\begin{array}{l}\text { Grade } 2 \\
\text { plus cortical } \\
\text { abnormalities }\end{array}$ \\
\hline Grade 4 & $\begin{array}{l}\text { Moderate to } \\
\text { severe periosteal } \\
\text { edema on T2 } \\
\text { Marrow edema on } \\
\text { T1 and T2 } \\
\text { Fracture line } \\
\text { apparent }\end{array}$ & $\begin{array}{l}\text { Positive } \\
\text { fracture line } \\
\text { on } \mathrm{T} 1 \text { and } \\
\mathrm{T} 2\end{array}$ & Fracture line & & $\begin{array}{l}\text { Severe } \\
\text { marrow or } \\
\text { periosteal } \\
\text { edema on } \mathrm{T} 1 \\
\text { or T2 plus } \\
\text { fracture line } \\
\text { on T1 or T2 } \\
\end{array}$ & $\begin{array}{l}\text { Displaced } \\
\text { fracture line }>2 \\
\mathrm{~mm}\end{array}$ & $\begin{array}{l}\text { Grade } 3 \text { plus } \\
\text { fracture line }\end{array}$ \\
\hline Grade 5 & & & $\begin{array}{l}\text { Callus at } \\
\text { endosteal and/ } \\
\text { or periosteal } \\
\text { surface of } \\
\text { cortical bone }\end{array}$ & & & Non-union & \\
\hline
\end{tabular}

Multiple grading scales exist for categorizing bone stress injury (BSI) on Magnetic Resonance Imaging (MRI). All were established primarily with adult patients.

*Short tau inversion recovery (STIR) and fat-suppressed T2 sequences may have higher sensitivity than T2. ${ }^{55}$

are the most useful. ${ }^{67}$ All patients in this case series had either soft tissue edema or an eccentric periosteal reaction, and four of five had edema that began near the entrance of the nutrient vessel into the medullary cavity. ${ }^{67}$ Identification of longitudinal injury may require more than one imaging modality. ${ }^{68}$ In select cases of symptomatic patients with normal MRI, CT may depict osteopenia representing early cortical stress injury. ${ }^{60}$
In cases where there is strong clinical suspicion but normal MRI and radiographs, clinicians must weigh the risk/benefit of additional imaging on the treatment recommendation for their patient. In some cases, additional imaging may be important for the patient, while in others, the additional imaging is not necessary. While MRI may be sufficient to detect most tibia BSI, inconsistencies in the literature on imaging findings to 


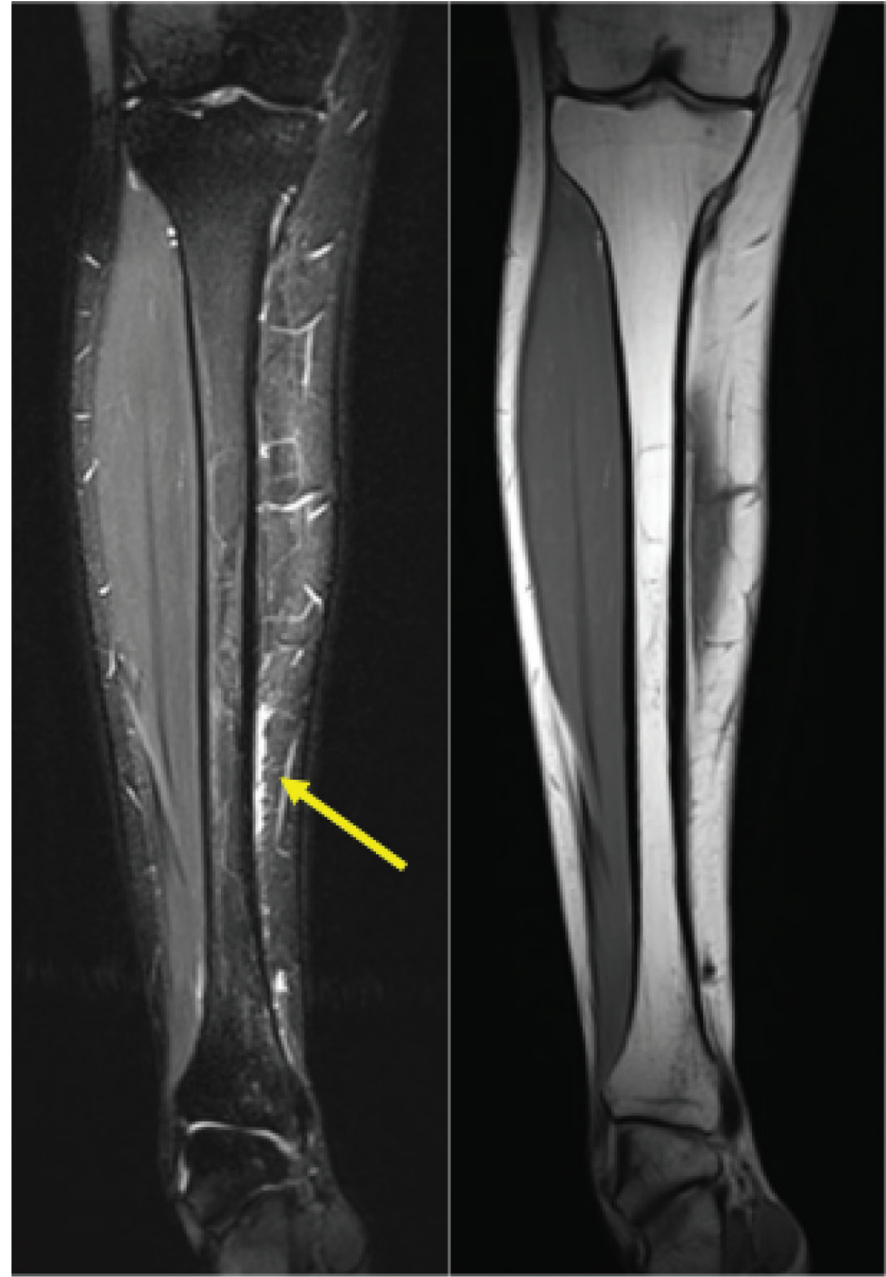

Fat-suppressed T2weighted image

T1-weighted image

Figure 1. MRI of Fredericson Grade 1 bone stress injury of tibia. Arrow demonstrates mild to moderate periosteal edema on fat-suppressed T2-weighted image (normal appearance on T1-weighted image).

clinical features highlight the value in future research to understand chronic leg pain. ${ }^{13}$

The use of MRI has greatly improved the ability of physicians to diagnose radiographically occult BSI as a source of tibial pain in adolescents. The benefits of the use of MRI are its high sensitivity and specificity without exposing the patient to radiation. The drawbacks of MRI include its expense, scan time in a confined space, and justification for its use when the results may not change the course of conservative

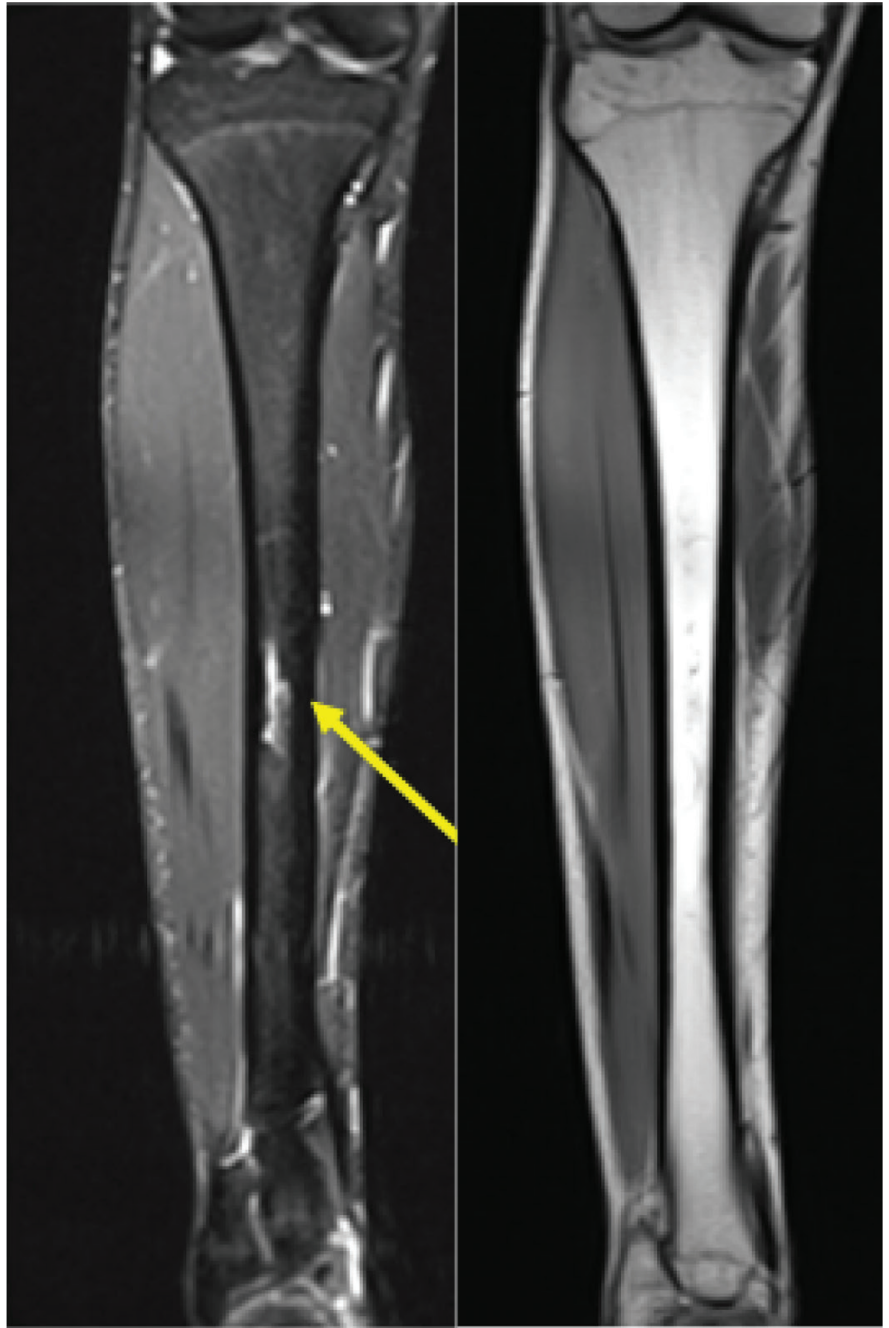

\section{Fat-suppressed T2- weighted image}

\section{T1-weighted image}

Figure 2. MRI of Fredericson Grade 2 bone stress injury of tibia. Arrow demonstrates marrow edema on fat-suppressed T2-weighted image (normal appearance on T1-weighted image).

treatment. As such, MRI is not always approved by insurance for acute use or before a course conservative treatment and rest.

\section{Bone Scintigraphy}

Bone scintigraphy (also known as bone scan) has long been used in the evaluation of BSIs. Bone scans will be positive before radiographic changes are demonstrated, ${ }^{69}$ with osteoblastic new bone formation represented by localized increased isotope uptake. Early studies 


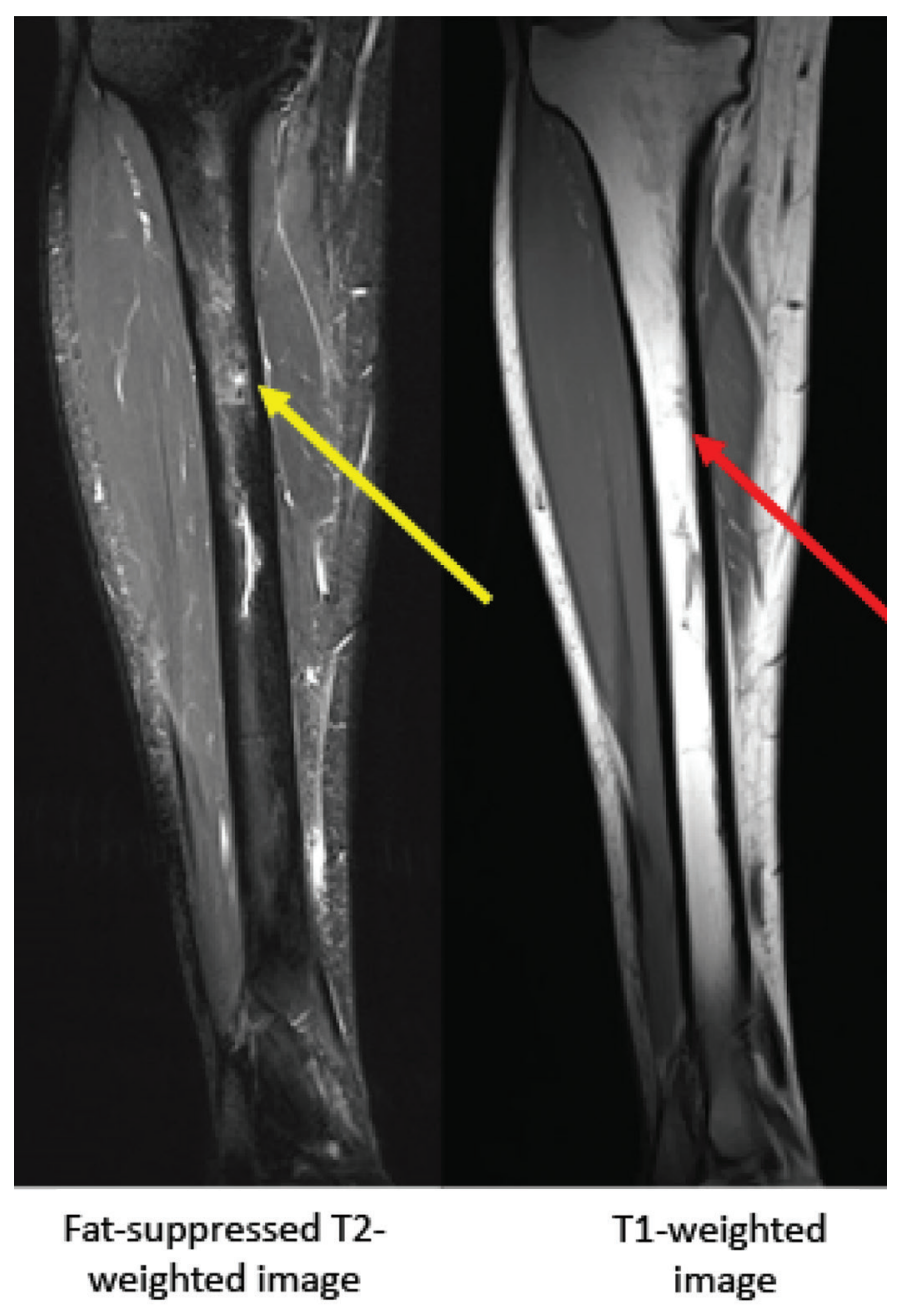

Figure 3. MRI of Fredericson Grade 3 bone stress injury of tibia. Arrows demonstrate marrow edema on fat-suppressed T2- and T1-weighted images.

suggested a sensitivity of $100 \%$ by injecting a radiotracer of $99 \mathrm{~m}$-Tc-methylene diphosphonate intravenously. ${ }^{38}$ Increased radiotracer activity often can be detected within 24 to 36 hours of the onset of fracture. The majority of the dose, however, is renally eliminated within six hours of injection. ${ }^{70}$

There have been several attempts to grade BSI and project recovery time based on scintigraphy with mixed results. Greaney and colleagues subjectively graded the spectrum of scintographic uptake into four levels graded as normal ( 0$)$ to $3+$, in an attempt to quantify the degree of bone involvement, then reviewed their findings based on trabecular and cortical findings and compared with radiography. ${ }^{71}$ The initial scintigraphic classification by Chisin and colleagues did not identify differences between classification and the clinical evolution of patients when separated into four grades. ${ }^{72}$ A modified version by Zwas and colleagues correlated recovery time across four grades of bone involvement. ${ }^{25}$ Castropil and colleagues compared bone scan with MRI and developed a quantitative evaluation index (QEI) that compared injured and non-injured legs, identifying a positive correlation between QEI to time for recovery. ${ }^{73}$

Because many early studies looking at BSI used bone scan as the gold standard, accurate representation of sensitivity and specificity of the test is lacking. A systematic review looking at the use of bone scan in lower extremity stress fractures in patients of all ages reported a sensitivity of 50-97\%, with specificity ranging from $33-98 \% .{ }^{27}$ False positives are a concern with bone scan. Any condition that causes increased bone turnover may be positive on this imaging technique, including infections, tumors, aseptic necrosis, trauma, and complex regional pain syndrome/reflex sympathetic dystrophy. ${ }^{58}$ Other disadvantages of bone scan include the length of time to perform the test, difficulty in determining the severity of BSI, and the high dose of radiation. It is estimated that the radiation from a single bone scan is equivalent to 60 two-view chest radiographs (effective radiation dose: $6.3 \mathrm{mSv}$ ). ${ }^{74}$ There is also a fairly high radiation load to the entire body from the radioactive isotope. It has been calculated that a 10 -yearold patient undergoing a bone scan will receive 3.9 $\mathrm{mSv}$, theoretically inducing a $0.04 \%$ increased risk for cancer. $^{75}$

There are limited data on the use of bone scintigraphy for evaluating tibial BSI in pediatric and adolescent age groups. Pediatric data for sensitivity and specificity are lacking. Since MRI scanners are readily available in most areas, perform with excellent sensitivity and specificity, and do not provide any radiation load concerns, the use of bone scan in the pediatric population should be reserved for rare clinical scenarios. 


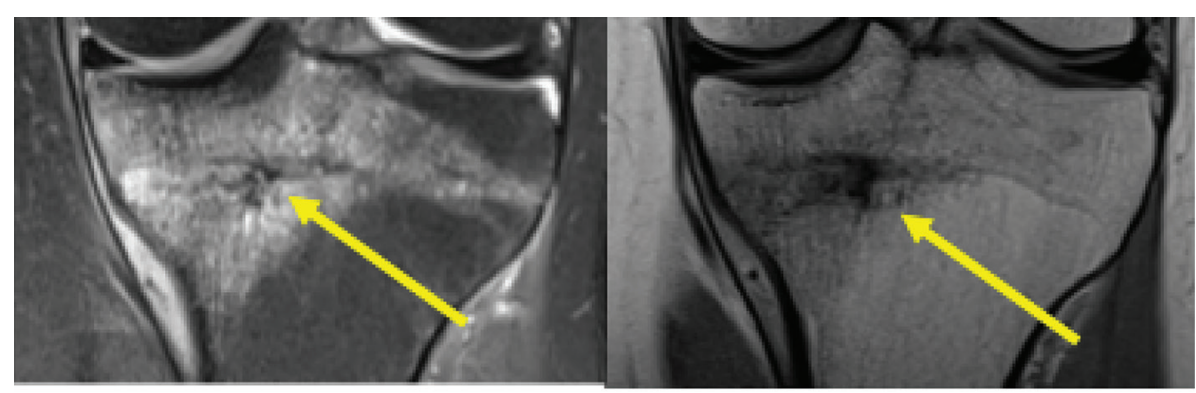

\section{Fat-suppressed T2- weighted image}

\section{T1-weighted image}

Figure 4. MRI of Fredericson Grade 4 bone stress injury of proximal tibia. Arrows demonstrate edema on fat-suppressed T2 and T1-weighted images, and a horizontal fracture line is apparent.

\section{Ultrasound}

\section{Musculoskeletal Ultrasound}

Musculoskeletal ultrasound (MSK US) is an inexpensive imaging technique that many sports medicine physicians now use in their clinical diagnosis of pathology.

Periosteal reactions of BSI can sometimes be visualized on ultrasound before bony callus is observed on plain radiographs, aiding in earlier diagnosis. ${ }^{76}$

MSK US can identify periosteal thickening, subcutaneous edema, calcified bone callus, hypervascular changes, and cortical irregularities that are associated with BSI. ${ }^{77}$ It has the ability to identify presence of hypoechoic calluses and buckling in the bony cortex more than other imaging modalities. ${ }^{57}$ Diagnostic ultrasound has a sensitivity of $43-99 \%$ and specificity of $13-79 \% .{ }^{27}$ The sensitivity of MSK US for identifying BSI on the posterior cortex of the tibia is low. ${ }^{57}$

Additional extension of MSK US includes visualization of increased blood flow and vascularization related to fracture pathology using Doppler technology. Changes in vascularity using power Doppler imaging may be helpful for the early diagnosis of BSI. ${ }^{78}$ Bodner and colleagues identified sonographic features of anatomy surrounding site of BSI, including presence of soft tissue edema, fluid collection, and increased vascularity. ${ }^{79}$

Imaging findings on MSK US frequently coincide with findings on MRI. ${ }^{79,80}$ Banal and colleagues established guidelines for MSK US diagnosis of metatarsal BSI defined as meeting two or more criteria: hypoechoic periosteal elevation above cortical bone, cortical disruption, or increased vascularity on power Doppler. ${ }^{81}$ These criteria had reported sensitivity of $83 \%$ and specificity of $76 \% .{ }^{81}$ Bianchi and Luong modified this algorithm and described five hallmarks of BSI: (1) periosteal thickening, (2) a calcified bone callus, (3) cortical irregularities, (4) subcutaneous edema, (5) hypervascular changes seen on color Doppler US. ${ }^{77}$ These studies, however, have not been reproduced with tibial BSI but highlight the potential utility of MSK US for diagnosing BSI.

Because of its relative diagnostic accuracy when compared with MRI, lack of exposure to ionizing radiation, portability, safety, point-of-care capability, and low cost, MSK US is recommended for clinical examination and should be considered an adjuvant imaging modality to utilize in addition to the traditional initial plain film evaluation. ${ }^{57}$

Limitations of MSK US include the inability to assess structures deep to the bone cortex such as marrow edema. However, many of the surface findings MSK US identifies may correlate with findings of bone marrow edema. ${ }^{57}$ As an in-office imaging modality, perhaps the greatest limitation is that there is intersonographer variability and a steep learning curve for clinicians. In general, the literature associated with 
MSK US imaging of pediatric BSI is lacking, but considering the safety and relative capabilities of MSK US, it is an imaging modality that should be included in future BSI research.

\section{Therapeutic Ultrasound}

Many rehabilitation specialists (e.g., physical therapists, athletic trainers) also have access to therapeutic ultrasound (TUS). TUS employs a low frequency range of 1-3 $\mathrm{mHz}$ that is not used for visualization of anatomic structures. ${ }^{82}$ Application of $1.5-2.0 \mathrm{~W} / \mathrm{cm}^{2}, 100 \%$ duty cycle for 1 minute over the suspected injury may create an increase in pain and heat in the damaged periosteum due to energy absorption; such increased pain and heat is considered a positive diagnostic test. ${ }^{83,84}$ TUS has been noted to provide positive findings 2-3 weeks prior to radiographic findings. ${ }^{85} \mathrm{In}$ a comparative study, TUS was less sensitive compared to bone scan, but more sensitive than radiography at detecting tibial BSI (75\% TUS, $100 \%$ bone scan, $22 \%$ radiograph) ${ }^{37}$ However, TUS was not as specific as bone scan or radiography $(67 \%, 100 \%$, $98 \%$, respectively). TUS fails to reveal many low-grade BSIs that can be identified by MRI and therefore is not considered a definitive diagnostic tool for BSI. ${ }^{30}$ There are no published BSI classification systems for TUS of the tibia. ${ }^{86}$

\section{Computed Tomography (CT)}

CT scans are sometimes selected for imaging of a tibial BSI following radiographs. There are few reports of the sensitivity and specificity of CT for the assessment of tibial BSIs in pediatric - particularly athletic populations. Like other imaging modalities, a grading system for assessment of BSI severity has been proposed. This grading system, however, was developed with a non-pediatric sample (age range: 19-37 years; mean age \pm standard deviation: 27.8 years \pm 5.4 ), though all participants completed regular competitive or recreational physical activity. ${ }^{60} \mathrm{CT}$ has shown superior imaging of the cortex over MRI and bone scan. However, MRI is more sensitive and specific than CT and bone scan on imaging soft tissue and marrow edema. ${ }^{60}$
$\mathrm{CT}$ provides diagnostic value in select cases of BSI or in shin pain with a differential diagnosis expanding beyond BSI, particularly when bone neoplasm is a possibility. In cases with negative MRI findings, CT can demonstrate the earliest signs of cortical stress injury that are occult on other imaging techniques. ${ }^{60}$ Furthermore, CT has been shown to be particularly sensitive at diagnosing longitudinal stress changes in the tibia. For example, one study ${ }^{87}$ reported the sensitivity of CT for longitudinal BSI as $82 \%$ (versus $73 \%$ for MRI), and a recent review ${ }^{56}$ rated $\mathrm{CT}$ as the modality of choice for longitudinal fracture lines. CT may also clarify lesion etiology including osteomyelitis with a Brodie abscess and various neoplasms such as osteoid osteoma. ${ }^{55,88}$ Malignant tumors in young adults present similarly to BSI and, in situations of adequate clinical suspicion, such a study can be useful. ${ }^{89}$ While useful in the cases of a broad differential for shin pain, BSI severity as assessed by CT scan has not been correlated with clinical severity or time to recovery. When compared to other imaging, CT grades for the same injury were lower than bone scans and MRI and higher than x-ray. ${ }^{15}$ This poor clinical correlation suggests the need for a new severity scale for CT scans of tibial BSI.

CT scans of pediatric and adolescent patients carry significant concern for radiation load and have been noted to carry 200-300 times the radiation load of a single radiograph. The effective radiation dose from a CT scan varies by area of the body studied but generally ranges from 2-8 $\mathrm{mSv}$ for most body regions. ${ }^{74} \mathrm{With}$ concerns about radiation load, modified protocols should be implemented in the pediatric population. CT may be indicated for those who are unable to undergo an MRI due to claustrophobia, implanted metal hardware or pacemaker, or an inability to remain still.

\section{Summary}

Tibial bone stress injuries are common within the adolescent athletic population and can have a significant impact on athletic activity. Exercise-induced atraumatic injury of the tibia has been referred to in the literature by many different diagnostic terms, creating confusion for clinicians and patients who attempt to appropriately 
Table 2. Grading Comparison of Imaging Modalities

\begin{tabular}{|c|c|c|c|c|c|c|}
\hline & X-ray & MSK US & Bone Scan & MRI & CT Scan & Treatment \\
\hline Grade 1 & Normal & $\begin{array}{l}\text { Periosteal swelling } \\
\text { Hyperechoic } \\
\text { periosteal elevation }\end{array}$ & $\begin{array}{l}\text { Poorly defined } \\
\text { area of increased } \\
\text { activity }\end{array}$ & Positive STIR & $\begin{array}{l}\text { Soft tissue mass } \\
\text { Periosteal surface }\end{array}$ & $\begin{array}{l}\text { Reduced } \\
\text { activity for 1-3 } \\
\text { weeks }\end{array}$ \\
\hline Grade 2 & $\begin{array}{l}\text { Normal } \\
\text { Periosteal } \\
\text { reaction } \\
\end{array}$ & $\begin{array}{l}\text { Periosteal elevation } \\
\text { Subcutaneous } \\
\text { edema }\end{array}$ & $\begin{array}{l}\text { More intense } \\
\text { but still poorly } \\
\text { defined activity } \\
\end{array}$ & $\begin{array}{l}\text { Positive STIR } \\
\text { Positive T2 }\end{array}$ & $\begin{array}{l}\text { Yellow } \\
\text { attenuation }\end{array}$ & 4-6 weeks rest \\
\hline Grade 3 & $\begin{array}{l}\mathrm{PNB}^{*}, \mathrm{ENB}^{\dagger} \\
\text { Periosteal } \\
\text { reaction }\end{array}$ & $\begin{array}{l}\text { Increased } \\
\text { vascularity } \\
\text { Periosteal elevation } \\
\text { Cortical thickening }\end{array}$ & $\begin{array}{l}\text { Areas of } \\
\text { increased } \\
\text { activity } \\
\text { Fusiform or } \\
\text { focal uptake }\end{array}$ & $\begin{array}{l}\text { Positive T1 } \\
\text { and T2 without } \\
\text { cortical break }\end{array}$ & $\begin{array}{l}\text { Osteopenia } \\
\text { Hypoattenuation }\end{array}$ & $8-12$ weeks rest \\
\hline Grade 4 & $\begin{array}{l}\text { Sclerosis } \\
\text { "Black line" } \\
\text { PNB, ENB }\end{array}$ & $\begin{array}{l}\text { Callous } \\
\text { Increased } \\
\text { vascularity on } \\
\text { doppler } \\
\text { Crack or fracture } \\
\text { line }\end{array}$ & Focal uptake & $\begin{array}{l}\text { Positive T1 } \\
\text { and T2 } \\
\text { Fracture line }\end{array}$ & Fracture line & $\begin{array}{l}4-6 \text { months } \\
\text { rest vs. surgical } \\
\text { fixation }\end{array}$ \\
\hline
\end{tabular}

${ }^{*} P N B$ - periosteal new bone; ${ }^{\dagger} E N B$ - endosteal new bone

manage the injury. Overuse injuries span a spectrum of severity ranging from periosteal irritation through frank fracture that go by many names both in the scientific discourse and clinic. Unification of terminology and grading allows for improved diagnosis, treatment, patient communication and return to play decision making. Consequently, we propose the use of the term "bone stress injury" (BSI) to describe various degrees of bone injury. Differences between imaging modalities exist. Based on review of available studies, we suggest using the Fredericson criteria for injury staging (Table 1$),{ }^{18}$ and fat-suppressed T2 sequences or STIR can be used in place of the T2-weighted sequences, with same descriptive findings applicable. ${ }^{55} \mathrm{~A}$ comparison of grading systems by imaging modality is shown in Table 2.

When evaluating patients with atraumatic tibial pain, clinicians should maintain a high level of suspicion for BSI. Appropriate imaging can lead to earlier diagnosis, which may result in shorter disability. Radiography should be used as the initial imaging modality. If the initial radiographs are within normal limits, but clinical suspicion is high for BSI, MRI is the preferred next imaging choice, offering high sensitivity and specificity without radiation exposure. Radiation load must be thoughtfully considered in the adolescent population, and physicians should be mindful of the potential cumulative effects when ordering additional imaging. Ultimately, physicians must weigh the costs, risks, and benefits of additional studies on patient outcomes.

We suggest the following directions for future study of tibial BSI in adolescents: (1) validation of MRI for diagnosis of and return to play timelines following tibial BSI, (2) further study of MRI vs. US for diagnosis and prediction of return to play timelines after tibial BSI, and (3) development of best-practice imaging guidelines and nomenclature for common overuse injuries of other bones. 


\section{Additional Links}

- The AMSSM National Fellow Online Lecture Series: High-Grade Stress Fractures: https://www.youtube.com/ watch? $\mathrm{v}=$ F3IemapSJzk

- The Image Gently Alliance: https://www.imagegently. org/

\section{Acknowledgement}

Thank you to radiologist, Dr. Richard Schwartz, for his review of images and expertise.

\section{References}

1. Tenforde AS, Kraus E, Fredericson M. Bone stress injuries in runners. Phys Med Rehabil Clin. 2016;27(1):139-149.

2. Iwamoto J, Sato Y, Takeda T, et al. Analysis of stress fractures in athletes based on our clinical experience. World J Orthop. 2011;2(1):7-12. doi: https://doi.org/10.5312/wjo.v2.i1.7.

3. Snyder RA, Koester MC, Dunn WR. Epidemiology of stress fractures. Clin Sports Med. 2006;25(1):37-52.

4. Ruddick GK, Lovell GA, Drew MK, et al. Epidemiology of bone stress injuries in Australian high performance athletes: a retrospective cohort study. J Sci Med Sport. 2019;22(10):1114-1118. doi: https://doi. org/10.1016/j.jsams.2019.06.008 [published Online First: 2019/07/17].

5. Patel P, Wheatcroft R, Park RJ, et al. The children of mothers with eating disorders. Clin Child Fam Psychol Rev. 2002;5(1):1-19. [published Online First: 2002/05/08].

6. Ashe MC, Davis JC. Bone health across the lifespan: implications for physical therapy practice. $J$ Womens Health. 2005;29(3):13-18.

7. Ohta-Fukushima M, Mutoh Y, Takasugi S, et al. Characteristics of stress fractures in young athletes under 20 years. J Sports Med Phys Fitness. 2002;42(2):198-206. [published Online First: 2002/05/29].

8. Saunier J, Chapurlat R. Stress fracture in athletes. Joint Bone Spine. 2018;85(3):307-310.

9. Boden BP, Osbahr DC. High-risk stress fractures: evaluation and treatment. J Am Acad Orthop Surg. 2000;8(6):344-353. doi: https:// doi.org/10.5435/00124635-200011000-00002 [published Online First: 2000/12/05]

10. Kaeding CC, Miller T. The comprehensive description of stress fractures: a new classification system. J Bone Joint Surg Am. 2013;95(13):1214-1220.

11. Gmachowska AM, Zabicka M, Pacho R, et al. Tibial stress injuries location, severity, and classification in magnetic resonance imaging examination. Pol J Radiol. 2018;83:e471-e81. doi: https://doi.org/10.5114/ pjr.2018.80218 [published Online First: 2019/01/19].

12. Sanderlin BW, Raspa RF. Common stress fractures. Am Fam Physician. 2003;68(8):1527-1532. [published Online First: 2003/11/05].

13. Batt ME, Ugalde V, Anderson MW, et al. A prospective controlled study of diagnostic imaging for acute shin splints. Med Sci Sports Exerc. 1998;30(11):1564-1571. doi: https://doi.org/10.1097/00005768199811000-00002 [published Online First: 1998/11/14].

14. Arendt EA, Griffiths HJ. The use of MR imaging in the assessment and clinical management of stress reactions of bone in high-performance athletes. Clin Sports Med. 1997;16(2):291-306. doi: https://doi. org/10.1016/s0278-5919(05)70023-5 [published Online First: 1997/04/01].

15. Beck BR, Bergman AG, Miner M, et al. Tibial stress injury: relationship of radiographic, nuclear medicine bone scanning, MR imaging, and CT Severity grades to clinical severity and time to healing. Radiology.
2012;263(3):81181-81188. doi: https://doi.org/10.1148/radiol.12102426 [published Online First: 2012/05/25].

16. Berger FH, de Jonge MC, Maas M. Stress fractures in the lower extremity: the importance of increasing awareness amongst radiologists. Eur $J$ Radiol. 2007;62(1):16-26.

17. Changstrom BG, Brou L, Khodaee M, et al. Epidemiology of stress fracture injuries among US high school athletes, 2005-2006 through 2012-2013. Am J Sports Med. 2015;43(1):26-33. doi: https://doi. org/10.1177/0363546514562739 [published Online First: 2014/12/07].

18. Fredericson M, Bergman AG, Hoffman KL, et al. Tibial stress reaction in runners: correlation of clinical symptoms and scintigraphy with a new magnetic resonance imaging grading system. Am J Sports Med. 1995;23(4):472-481.

19. Heyworth BE, Green DW. Lower extremity stress fractures in pediatric and adolescent athletes. Curr Opin Pediatr. 2008;20(1):58-61.

20. Johnell O, Rausing A, Wendeberg B, et al. Morphological bone changes in shin splints. Clin Orthop Relat Res. 1982(167):180-184. [published Online First: 1982/07/01].

21. Jones BH. Overuse injuries of the lower extremities associated with marching, jogging, and running: a review. Mil Med. 1983;148(10): 783-787. [published Online First: 1983/10/01].

22. Stickley CD, Hetzler RK, Kimura IF, et al. Crural fascia and muscle origins related to medial tibial stress syndrome symptom location. Med Sci Sports Exerc. 2009;41(11):1991-1996. doi: https://doi.org/10.1249/ MSS.0b013e3181a6519c [published Online First: 2009/10/09].

23. Ohnishi J. Differentiating tibial stress fracture from shin splints by using MRI. Sports Orthop Traumatol. 2015;31(3):188-194.

24. Gaeta M, Minutoli F, Mazziotti S, et al. Diagnostic imaging in athletes with chronic lower leg pain. AJR Am J Roentgenol. 2008;191(5): 1412-1419. doi: https://doi.org/10.2214/ajr.07.3379 [published Online First: 2008/10/23].

25. Zwas ST, Elkanovitch R, Frank G. Interpretation and classification of bone scintigraphic findings in stress fractures. J Nucl Med. 1987;28(4):452-457. [published Online First: 1987/04/01].

26. Nussbaum ED, Gatt CJ, Jr., Epstein R, et al. Validation of the Shin Pain Scoring System: a novel approach for determining tibial bone stress injuries. Orthop J Sports Med. 2019;7(10):2325967119877803. doi: https://doi.org/10.1177/2325967119877803 [published Online First: 2019/11/07].

27. Wright AA, Hegedus EJ, Lenchik L, et al. Diagnostic accuracy of various imaging modalities for suspected lower extremity stress fractures: a systematic review with evidence-based recommendations for clinical practice. Am J Sports Med. 2016;44(1):255-263. doi: https://doi.org/10.1177/0363546515574066 [published Online First: 2015/03/26]

28. Niemeyer P, Weinberg A, Schmitt H, et al. Stress fractures in the juvenile skeletal system. Int J Sports Med. 2006;27(3):242-249. doi: https://doi. org/10.1055/s-2005-865649 [published Online First: 2006/03/17].

29. Sallis RE, Jones K. Stress fractures in athletes: how to spot this underdiagnosed injury. Postgrad Med. 1991;89(6):185-192.

30. Shin AY, Morin WD, Gorman JD, et al. The superiority of magnetic resonance imaging in differentiating the cause of hip pain in endurance athletes. Am J Sports Med. 1996;24(2):168-176. doi: https://doi. org/10.1177/036354659602400209 [published Online First: 1996/03/01].

31. Icrp, Khong PL, Ringertz H, et al. ICRP publication 121: radiological protection in paediatric diagnostic and interventional radiology. Ann ICRP. 2013;42(2):1-63. doi: https://doi.org/10.1016/j.icrp.2012.10.001 [published Online First: 2012/12/12].

32. Bencardino JT, Stone TJ, Roberts CC, et al. ACR Appropriateness Criteria((R)) Stress (Fatigue/Insufficiency) Fracture, Including Sacrum, Excluding Other Vertebrae. J Am Coll Radiol. 2017;14(5s):S293-S306. doi: https://doi.org/10.1016/j.jacr.2017.02.035 [published Online First: 2017/05/06]. 
33. Patel NM, Mai DH, Ramme AJ, et al. Is the incidence of paediatric stress fractures on the rise? Trends in New York State from 2000 to 2015. J Pediatr Orthop B. 2020;29(5):499-504.

34. Harmon KG. Lower extremity stress fractures. Clin J Sport Med. 2003;13(6):358-364.

35. Miller TL, Jamieson M, Everson S, et al. Expected time to return to athletic participation after stress fracture in division I Collegiate athletes. Sports Health. 2018;10(4):340-344. doi: https://doi. org/10.1177/1941738117747868 [published Online First: 2017/12/15]

36. Bone marrow changes in stress injuries. Seminars in musculoskeletal radiology; 2011. (C) Thieme Medical Publishers.

37. Giladi M, Nili E, Ziv Y, et al. Comparison between radiography, bone scan, and ultrasound in the diagnosis of stress fractures. Mil Med. 1984;149(8):459-461. [published Online First: 1984/08/01].

38. Meurman KO, Elfving S. Stress fracture in soldiers: a multifocal bone disorder. A comparative radiological and scintigraphic study. Radiology. 1980;134(2):483-487. doi: https://doi.org/10.1148/ radiology.134.2.7352236 [published Online First: 1980/02/01].

39. Kijowski R, Choi J, Shinki K, et al. Validation of MRI classification system for tibial stress injuries. AJR Am J Roentgenol. 2012;198(4):878-884.

40. Kiuru MJ, Pihlajamaki H, Hietanen $\mathrm{H}$, et al. MR imaging, bone scintigraphy, and radiography in bone stress injuries of the pelvis and the lower extremity. Acta Radiol. 2002;43(2):207-212.

41. Markey KL. Stress fractures. Clin Sports Med. 1987;6(2):405-425. [published Online First: 1987/04/01]

42. Schilcher J, Bernhardsson M, Aspenberg P. Chronic anterior tibial stress fractures in athletes: No crack but intense remodeling. Scand J Med Sci Sports. 2019;29(10):1521-1528.

43. Swischuk LE, Jadhav SP. Emergency Musculoskeletal Imaging in Children. Springer; 2013.

44. Papadimitriou NG, Christophorides J, Papadimitriou A, et al. Stress fractures in children: a review of 37 cases. Eur J Orthop Surg Traumatol. 2007;17(2):131-137.

45. Bergman AG, Fredericson $\mathrm{M}$, Ho C, et al. Asymptomatic tibial stress reactions: MRI detection and clinical follow-up in distance runners. AJR Am J Roentgenol. 2004;183(3):635-638. doi: https://doi.org/10.2214/ ajr.183.3.1830635 [published Online First: 2004/08/31].

46. Savoca CJ. Stress fractures. A classification of the earliest radiographic signs. Radiology. 1971;100(3):519-524. doi: https://doi. org/10.1148/100.3.519 [published Online First: 1971/09/01]

47. Fottner A, Baur-Melnyk A, Birkenmaier C, et al. Stress fractures presenting as tumours: a retrospective analysis of 22 cases. Int Orthop. 2009;33(2):489-492. doi: https://doi.org/10.1007/s00264-007-0488-5 [published Online First: 2007/12/18]

48. Mulligan ME. The "gray cortex": an early sign of stress fracture. Skeletal Radiol. 1995;24(3):201-203.

49. Hughes JM, Popp KL, Yanovich R, et al. The role of adaptive bone formation in the etiology of stress fracture. Exp Biol Med. 2017;242(9):897-906

50. Gereige R, Kumar M. Bone lesions: benign and malignant. Pediatr Rev. 2010;31(9):355.

51. Wyers MR. Evaluation of pediatric bone lesions. Pediatr Radiol. 2010;40(4):468-473.

52. Tins BJ, Garton M, Cassar-Pullicino VN, et al. Stress fracture of the pelvis and lower limbs including atypical femoral fractures - a review. Insights Imaging. 2015;6(1):97-110.

53. Liong S, Whitehouse R. Lower extremity and pelvic stress fractures in athletes. Br J Radiol. 2012;85(1016):1148-1156.

54. Nachtrab O, Cassar-Pullicino VN, Lalam R, et al. Role of MRI in hip fractures, including stress fractures, occult fractures, avulsion fractures. Eur J Radiol. 2012;81(12):3813-3823. doi: https://doi.org/10.1016/j. ejrad.2011.04.003 [published Online First: 2011/05/03].
55. Fredericson M, Jennings F, Beaulieu C, et al. Stress fractures in athletes. Top Magn Reson Imaging. 2006;17(5):309-325.

56. Matcuk GR, Mahanty SR, Skalski MR, et al. Stress fractures: pathophysiology, clinical presentation, imaging features, and treatment options. Emerg Radiol. 2016;23(4):365-375.

57. Fukushima Y, Ray J, Kraus E, et al. A review and proposed rationale for the use of ultrasonography as a diagnostic modality in the identification of bone stress injuries. J Ultrasound Med. 2018;37(10):2297-2307. doi: https://doi.org/10.1002/jum.14588 [published Online First: 2018/04/15]

58. Kiuru MJ, Pihlajamäki H, Ahovuo J. Bone stress injuries. Acta Radiol. 2004;45(3):317-326.

59. Nattiv A, Kennedy G, Barrack MT, et al. Correlation of MRI grading of bone stress injuries with clinical risk factors and return to play: a 5-year prospective study in collegiate track and field athletes. Am J Sports Med. 2013;41(8):1930-1941. doi: https://doi.org/10.1177/0363546513490645 [published Online First: 2013/07/05].

60. Gaeta M, Minutoli F, Scribano E, et al. CT and MR imaging findings in athletes with early tibial stress injuries: comparison with bone scintigraphy findings and emphasis on cortical abnormalities. Radiology. 2005;235(2):553-561. doi: https://doi.org/10.1148/radiol.2352040406 [published Online First: 2005/04/29]

61. Lazzarini KM, Troiano RN, Smith RC. Can running cause the appearance of marrow edema on MR images of the foot and ankle? Radiology. 1997;202(2):540-542. doi: https://doi.org/10.1148/ radiology.202.2.9015087 [published Online First: 1997/02/01].

62. Magnusson HI, Ahlborg HG, Karlsson C, et al. Low regional tibial bone density in athletes with medial tibial stress syndrome normalizes after recovery from symptoms. Am J Sports Med. 2003;31(4):596-600. doi: https://doi.org/10.1177/03635465030310042001 [published Online First: 2003/07/16].

63. Matheson GO, Clement DB, McKenzie DC, et al. Scintigraphic uptake of $99 \mathrm{mTc}$ at non-painful sites in athletes with stress fractures. The concept of bone strain. Sports Med. 1987;4(1):65-75. doi: https://doi. org/10.2165/00007256-198704010-00007 [published Online First: 1987/01/01].

64. Hadid A, Moran DS, Evans RK, et al. Tibial stress changes in new combat recruits for special forces: patterns and timing at MR imaging. Radiology. 2014;273(2):483-490. doi: https://doi.org/10.1148/radiol.14131882 [published Online First: 2014/07/16]

65. Anderson MW, Ugalde V, Batt M, et al. Shin splints: MR appearance in a preliminary study. Radiology. 1997;204(1):177-180. doi: https:// doi.org/10.1148/radiology.204.1.9205242 [published Online First: 1997/07/01].

66. Smith R, Moghal M, Newton J, et al. Negative magnetic resonance imaging in three cases of anterior tibial cortex stress fractures. Skeletal Radiol. 2017;46(12):1775-1782.

67. Craig JG, Widman D, van Holsbeeck M. Longitudinal stress fracture: patterns of edema and the importance of the nutrient foramen. Skeletal Radiol. 2003;32(1):22-27. doi: https://doi.org/10.1007/s00256-002-0597-6 [published Online First: 2003/01/15].

68. Jeske J, Lomasney L, Demos T, et al. Longitudinal tibial stress fracture Orthopedics. 1996;19(3):263; 66; 68; 70 .

69. Prather JL, Nusynowitz ML, Snowdy HA, et al. Scintigraphic findings in stress fractures. J Bone Joint Surg Am. 1977;59(7):869-874. [published Online First: 1977/10/01].

70. Manzil FFP, Baldwin J, Bag AK. Pediatric skeletal scintigraphy: what a general radiologist needs to know. Curr Probl Diagn Radiol. 2018;47(4):270-281.

71. Greaney RB, Gerber FH, Laughlin RL, et al. Distribution and natural history of stress fractures in U.S. Marine recruits. Radiology. 1983;146(2):339-346. doi: https://doi.org/10.1148/ radiology.146.2.6217486 [published Online First: 1983/02/01]. 
72. Chisin R, Milgrom C, Giladi M, et al. Clinical significance of nonfocal scintigraphic findings in suspected tibial stress fractures. Clin Orthop Relat Res. 1987(220):200-205. [published Online First: 1987/07/01].

73. Castropil W, Guimaraes A, Buchpiguel CA. Prognostic value of focal scintigraphic findings in clinically suspected cases of tibial stress fracture. Radiol Bras 2018;51(4):225-230. doi: https://doi.org/10.1590/01003984.2017.0028 [published Online First: 2018/09/12].

74. Mettler Jr FA, Huda W, Yoshizumi TT, et al. Effective doses in radiology and diagnostic nuclear medicine: a catalog. Radiology. 2008;248(1):254-263.

75. Fahey FH, Treves ST, Adelstein SJ. Minimizing and communicating radiation risk in pediatric nuclear medicine. J Nucl Med. 2011;52(8): 1240-1251. doi: https://doi.org/10.2967/jnumed.109.069609 [published Online First: 2011/07/19].

76. Moraux A, Gitto S, Bianchi S. Ultrasound features of the normal and pathologic periosteum. J Ultrasound Med. 2019;38(3):775-784. doi: https://doi.org/10.1002/jum.14762 [published Online First: 2018/09/24].

77. Bianchi S, Luong DH. Stress fractures of the calcaneus diagnosed by sonography: report of 8 cases. J Ultrasound Med. 2018;37(2):521-529. doi: https://doi.org/10.1002/jum.14276 [published Online First: 2017/06/13]

78. Rawool NM, Goldberg BB, Forsberg F, et al. Power Doppler assessment of vascular changes during fracture treatment with low-intensity ultrasound. J Ultrasound Med. 2003;22(2):145-153.

79. Bodner G, Stockl B, Fierlinger A, et al. Sonographic findings in stress fractures of the lower limb: preliminary findings. Eur Radiol. 2005;15(2):356-359. doi: https://doi.org/10.1007/s00330-004-2525-8 [published Online First: 2004/10/27].

80. Moran DS, Evans RK, Hadad E. Imaging of lower extremity stress fracture injuries. Sports Med. 2008;38(4):345-356.
81. Banal F, Gandjbakhch F, Foltz V, et al. Sensitivity and specificity of ultrasonography in early diagnosis of metatarsal bone stress fractures: a pilot study of 37 patients. J Rheumatol. 2009;36(8):1715-1719.

82. Hoglund LT, Silbernagel KG, Taweel NR. Distal fibular stress fracture in a female recreational athlete: a case report with musculoskeletal ultrasound imaging findings. Int J Sports Phys Ther. 2015;10(7): 1050-1058. [published Online First: 2015/12/18].

83. Boam WD, Miser WF, Yuill SC, et al. Comparison of ultrasound examination with bone scintiscan in the diagnosis of stress fractures. J Am Board Fam Pract. 1996;9(6):414-417.

84. Papalada A, Malliaropoulos N, Tsitas K, et al. Ultrasound as a primary evaluation tool of bone stress injuries in elite track and field athletes. Am J Sports Med. 2012;40(4):915-919. doi: https://doi. org/10.1177/0363546512437334 [published Online First: 2012/ 03/01].

85. Nitz AJ, Scoville CR. Use of ultrasound in early detection of stress fractures of the medial tibial plateau. Mil Med. 1980;145(12):844-846. [published Online First: 1980/12/01].

86. Miller T, Kaeding CC, Flanigan D. The classification systems of stress fractures: a systematic review. Phys Sportsmed. 2011;39(1):93-100. doi: https://doi.org/10.3810/psm.2011.02.1866 [published Online First: 2011/03/08].

87. Feydy A, Drapé J-L, Beret E, et al. Longitudinal stress fractures of the tibia: comparative study of CT and MR imaging. Eur Radiol. 1998;8(4):598-602

88. Swee RG, McLeod RA, Beabout JW. Osteoid osteoma: detection, diagnosis, and localization. Radiology. 1979;130(1):117-123.

89. Somer K, Meurman K. Computed tomography of stress fractures. J Comput Assist Tomogr. 1982;6(1):109-115. 